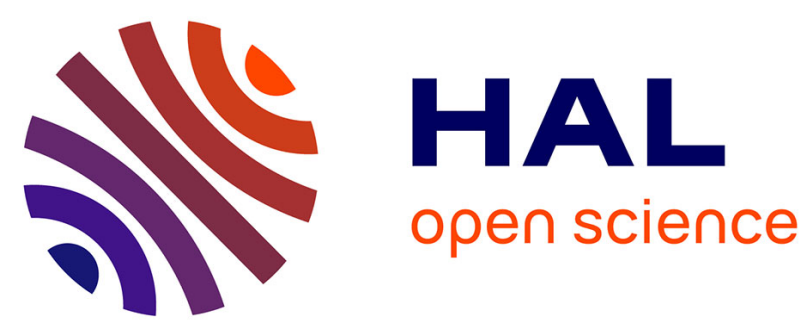

\title{
MÖSSBAUER STUDIES ON DAMAGE SITES OF ISOTOPE-SEPARATOR-IMPLANTED IMPURITY ATOMS IN SILICON
}

A. Nylandsted Larsen, G. Weyer, B. Deutch, E. Antoncik, H. Loft Nielsen

\section{- To cite this version:}

A. Nylandsted Larsen, G. Weyer, B. Deutch, E. Antoncik, H. Loft Nielsen. MÖSSBAUER STUDIES ON DAMAGE SITES OF ISOTOPE-SEPARATOR-IMPLANTED IMPURITY ATOMS IN SILICON. Journal de Physique Colloques, 1976, 37 (C6), pp.C6-883-C6-887. 10.1051/jphyscol:19766187 . jpa-00216711

\section{HAL Id: jpa-00216711 https://hal.science/jpa-00216711}

Submitted on 1 Jan 1976

HAL is a multi-disciplinary open access archive for the deposit and dissemination of scientific research documents, whether they are published or not. The documents may come from teaching and research institutions in France or abroad, or from public or private research centers.
L'archive ouverte pluridisciplinaire HAL, est destinée au dépôt et à la diffusion de documents scientifiques de niveau recherche, publiés ou non, émanant des établissements d'enseignement et de recherche français ou étrangers, des laboratoires publics ou privés. 


\title{
MÖSSBAUER STUDIES ON DAMAGE SITES OF ISOTOPE-SEPARATOR- IMPLANTED IMPURITY ATOMS IN SILICON
}

\author{
A. NYLANDSTED LARSEN, G. WEYER, B. I. DEUTCH, E. ANTONCIK, \\ and
}

H. LOFT NIELSEN

Institute of Physics, University of Aarhus, DK-8000 Aarhus C, Denmark

\begin{abstract}
Résumé - En utilisant la radiation $\gamma$ Mössbauer de $24 \mathrm{keV}$ de ${ }^{119} \mathrm{Sn}$, différents sites de dommage dans le silicium ont été étudiés. Le niveau Mössbauer était peuplé de la décroissance radioactive de ${ }^{119 m} \mathrm{Te}$. Des dommages par irradiation ont été créés par implantation (à l'aide d'un séparateur d'isotopes) des noyaux de la source radioactive. Le comportement de l'implantation et l'occupation des sites endommagés sont différents pour les implantations de Te ou de $\mathbf{S b}$ et $\mathbf{S n}$. Tandis que $\mathbf{S b}$ ou Sn se trouvent en prédominance sur des sites substitutionels, interstitiels et de dommage. Des expériences de recuit utilisant la chaîne de décroissance $119 \mathrm{~m} \mathrm{Te} \rightarrow{ }^{119} \mathrm{Sb} \rightarrow 119 \rightarrow \mathrm{Sn}$ révèlent différentes propriétés de recuit pour $\mathrm{Te}$ et $\mathrm{Sb}$ pour les mêmes sites de dommage. On trouve que les agglomérats endommagés de Te dans le silicium formés par l'implantation de Te sont très stables. Ces mêmes agglomérats contenant $\mathrm{Sb}$ (provenant de la décroissance radioactive de Te) recuisent entre 400 et $600{ }^{\circ} \mathrm{C}$. On a trouvé que l'oxygène contenu dans le cristal implanté avait une grande influence sur la formation des agglomérats endommagés. On suggère que ceci est dû à un mécanisme indirect de piégeage des lacunes par les atomes d'oxygène.
\end{abstract}

\begin{abstract}
Using the 24-keV Mössbauer $\gamma$ radiation of ${ }^{119} \mathrm{Sn}$, different damage sites in silicon have been studied. The Mössbauer level was populated from the radioactive decay of $119 \mathrm{mTe}$. Radiation damage was created by isotope-separator implantation of the radioactive-source nuclei. The implantation behaviour and the occupation of damage sites are different for implantations of Te or of $\mathrm{Sb}$ and $\mathrm{Sn}$. While $\mathrm{Sb}$ or $\mathrm{Sn}$ predominantly end on substitutional sites, Te is distributed over substitutional, interstitial, and damage sites. Annealing experiments utilizing the decay chain $119 \mathrm{~m} \mathrm{Te} \rightarrow{ }^{119} \mathrm{Sb} \rightarrow{ }^{19} \mathrm{Sn}$ reveal different annealing properties for $\mathrm{Te}$ and $\mathrm{Sb}$ at the same damage sites. Te-damage agglomerates in silicon formed by the implantation of $\mathrm{Te}$ are found to be very stable. The same agglomerates containing $\mathrm{Sb}$ (from the radioactive decay of $\mathrm{Te}$ ) anneal between 400 and $600^{\circ} \mathrm{C}$. A large influence of the oxygen content of the host crystal on the formation of the damage agglomerates was found. This is suggested to be due to an indirect mechanism of the trapping of vacancies by oxygen atoms.
\end{abstract}

1. Introduction. - Isotope-separator implantation of radioactive Te Mössbauer-source nuclei in silicon and other group-IV elements has been reported by two groups. Hafemeister and de Waard [1, 2] implanted ${ }^{129 \mathrm{~m}} \mathrm{Te}$ and measured on the Mössbauer transition of ${ }^{129} \mathrm{I}$. In our laboratory, ${ }^{119 m} \mathrm{Te}$ was implanted [3,4]. The electronic structures of the two Mössbauer atoms ${ }^{129} \mathrm{I}$ and ${ }^{119} \mathrm{Sn}$, respectively, are different, but their local environment is determined by the implantation properties of $\mathrm{Te}$. Therefore, the hyperfine structures measured in both experiments should be due to the interaction of the impurity atoms with the same configuration of surroundings if no lattice relaxation occurs. In both experiments, Mössbauer spectra with two broad lines were observed which showed close similarities in isomer shift. The intensity ratios for these lines were, however, different. From a comparison of Mössbauer and channeling experiments on $\mathrm{Sn}$ and Te implants, the lines with lower electron density at the nucleus were attributed to substitutional Te sites [3]. The variation of the electron densities for
Sn and I on substitutional sites in group-IV elements are well understood $[5,6]$. No unambiguous lattice location could be concluded for the second lines of high electron density, however.

In this paper it is shown that the spectra for ${ }^{119 \mathrm{~m}} \mathrm{Te}$ implants in silicon can be further structurized. Especially the "substitutional line" is shown to consist of two lines, one of which is due to radiation damage.

2. Experimental. - Implantations of ${ }^{119 \mathrm{~m}} \mathrm{Te}$ were carried out with an isotope separarator at an energy of $60 \mathrm{keV}$. The radioactivity was obtained by procedures similar to those described in ref. [3]. N-type silicon single crystals grown by different methods were implanted. Resonance-counting technique [7] was applied in the Mössbauer measurements.

3. Results and Data Treatment. - The results from the analysis of the Mössbauer spectra are given in Table I in comparison to spectra from implanted ${ }^{119 \mathrm{~m}} \mathrm{Sn}$ and ${ }^{119} \mathrm{Sb}$ in silicon (from ref. [3]). The A1, 
TABLE I

Results from implantations in silicon

\begin{tabular}{|c|c|c|c|c|c|c|c|c|c|c|c|c|c|c|c|c|c|}
\hline & & & \multicolumn{3}{|c|}{$\mathrm{A} 1$} & \multicolumn{3}{|c|}{$\mathrm{A} 2$} & \multicolumn{3}{|c|}{ A3 } & \multicolumn{3}{|c|}{ A4 } & \multicolumn{3}{|c|}{ A5 } \\
\hline \multirow{2}{*}{$\begin{array}{l}\text { Impl. } \\
\text { impurity }\end{array}$} & \multirow{2}{*}{$\begin{array}{l}\text { Impl. dose } \\
\text { atoms } / \mathrm{cm}^{2}\end{array}$} & Impl. & $I S$ & $\Gamma$ & $I$ & $I S$ & $\Gamma$ & $I$ & $I S$ & $\Gamma$ & $I$ & $I S$ & $\Gamma$ & $I$ & $I S$ & $\Gamma$ & $I$ \\
\hline & & ${ }^{\circ} \mathrm{C}$ & \multicolumn{3}{|c|}{$\mathrm{mm} / \mathrm{s}$} & \multicolumn{3}{|c|}{$\mathrm{mm} / \mathrm{s}$} & \multicolumn{3}{|c|}{$\mathrm{mm} / \mathrm{s}$} & \multicolumn{3}{|c|}{$\mathrm{mm} / \mathrm{s}$} & \multicolumn{3}{|c|}{$\mathrm{mm} / \mathrm{s}$} \\
\hline $\begin{array}{l}119 \mathrm{~m} \mathrm{Te}(1) \\
119 \mathrm{~m} \mathrm{Sn}(1) \\
119 \mathrm{mSb}(2)\end{array}$ & $\mid \begin{array}{r}<1 \times 10^{13} \\
1 \times 10^{14} \\
5 \times 10^{14}\end{array}$ & $\begin{array}{r}20 \\
20 \\
400\end{array}$ & $0.9 *$ & $1.0 *$ & $0.05(2)$ & $\begin{array}{l}1.84^{*} \\
1.87(4) \\
1.9(1)\end{array}$ & $\mid \begin{array}{l}1.0^{*} \\
0.99(5) \\
1.4(2)\end{array}$ & $\begin{array}{l}0.51(5) \\
1.0 \\
1.0\end{array}$ & $2.61 *$ & $1.0 *$ & $0.33(5)$ & $3.35^{*}$ & $1.0 *$ & $0.06(3)$ & $4.41 *$ & $1.0^{*}$ & $0.05(2)$ \\
\hline
\end{tabular}

(1) n-type silicon single crystals $(5 \Omega \mathrm{cm})$, vacuum-float zone, cut perpendicular to $\langle 100\rangle$.

(2) n-type silicon single crystal $(7 \Omega \mathrm{cm})$, float zone, cut perpendiculat to $\langle 111>$.

* Fixed parameter in the least-squares fit.

$I S$ is relative to $\mathrm{SnO}_{2}$, intensities normalized to $\sum_{i} I_{\mathrm{A}_{i}}=1$.

A2, ..., A5 represent the emission lines from the sources. The fits to the experimental data for the ${ }^{119} \mathrm{Sb}$ and ${ }^{119} \mathrm{Sn}$ implants are two-line fits due to a quadrupole splitting in the $\mathrm{SnO}_{2}$ absorber material. The splitting of the two lines, their intensity ratios and linewidths, $\Gamma$, have been fixed to known values. Thus only the isomer shift and line intensity have been varied in these fits. The data indicate that single lines are emitted from the sources; these are known to originate from impurity atoms on undisturbed substitutional lattice sites [3]. From the spectrum of the ${ }^{119}$ Te implant, it can be seen that several more lattice positions are occupied. The spectrum has been fitted assuming five individual emission lines for the source,

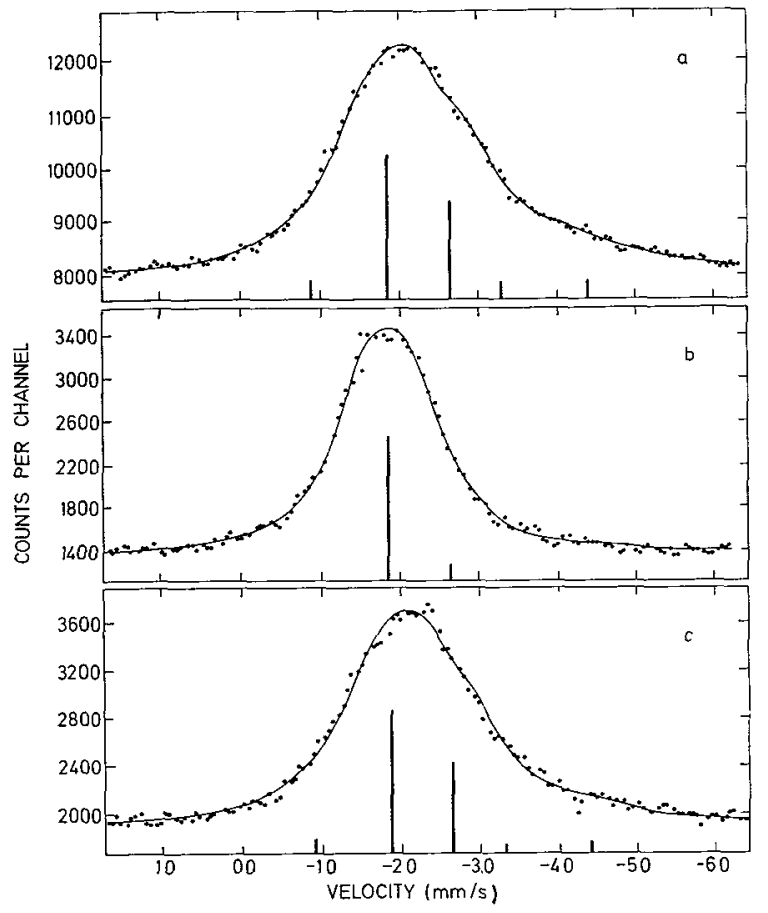

Mössbauer spectra of $119 \mathrm{~m} \mathrm{Te}$ in silicon, $(a)$ measured $60 \mathrm{~h}$ after room-temperature implantation, $(b)$ measured within $12 \mathrm{~h}$ after annealing at $600^{\circ} \mathrm{C},(c)$ measured $\geqslant 200 \mathrm{~h}$ after annealing at $700^{\circ} \mathrm{C}$. Line positions and intensities from a least-squares fit are indicated by bars. one of them being the well-known substitutional line Again the absorber parameters have been taken into account ; moreover, in the fit, the isomer shifts have been fixed to values (as inserted in the figure) extracted from a larger number of experimental data (this paper, Refs. [3, 4], and a forthcoming paper). In these experiments, several implantation conditions, e. g., implantation temperature and dose, have been varied resulting in different intensity ratios for the individual lines. Therefore, in some of these spectra, individual lines have been better resolved than in the case discussed here. Also, these lines could be distinguished by different dependences on implantation parameters. As all the measured spectra could be fitted satisfactorily with the same set of parameters, this fitting procedure seems to be justified even if resolution and/or statistical accuracy in a single spectrum may not be sufficient to establish the existence of five lines. Of course, from a fit to a single spectrum, some ambiguity is left as to what extent an individual line actually may represent a distribution of more than one line. In this connection it should be mentioned that the lines labelled $A 1$ and $A 4$ in table $I$ are less well-known than are the lines $\mathrm{A} 3$ and $\mathrm{A} 5$.

The radioactive decay chain

$$
{ }^{119 \mathrm{~m}} \mathrm{Te}(4,7 \mathrm{~d}) \rightarrow{ }^{119} \mathrm{Sb}(38 \mathrm{~h}) \rightarrow{ }^{119} \mathrm{Sn}
$$

allows a study of the annealing properties of both $\mathrm{Te}$ and $\mathrm{Sb}$ in the same lattice positions as occupied by the implanted ${ }^{119 m} \mathrm{Te}$ : for the implanted ${ }^{119 \mathrm{~m}} \mathrm{Te}$ in radioactive equilibrium with its decay products ( $\gtrsim 60 \mathrm{~h}$ after the implantation), two different types of annealing experiments can be performed. If the annealing time and measuring time following the annealing are short compared to the half-life of ${ }^{119} \mathrm{Sb}$, the intensity of the measured Mössbauer $\gamma$ radiation comes from decaying $\mathrm{Sb}$ atoms annealed as $\mathrm{Sb}$ atoms. On the other hand, if measuring is performed after a time long compared to the $\mathrm{Sb}$ half-life, then the $\gamma$ radiation stems from $\mathrm{Sb}$ atoms annealed as Te atoms. Thus the delay of the measuring period with respect to the time of a short annealing period determines whether 
the annealing properties of $\mathrm{Sb}$ or $\mathrm{Te}$ are measured in a Mössbauer experiment.

The resulting spectra from these two types of annealing experiments are shown in the figure. Compared to the spectrum of the unannealed sample (a), the disappearence of lines A1, A3, A4, and A5 after a 20-min annealing at $600^{\circ} \mathrm{C}$ is obvious in spectrum $b$. As the delay and measuring time for this spectrum was short compared to the half-life of ${ }^{119} \mathrm{Sb}$, the annealing properties are those of $\mathrm{Sb}$. Spectrum $\mathrm{c}$ obtained after annealing at $700{ }^{\circ} \mathrm{C}$ but long delay times proves that hardly any effect of annealing is observed for $\mathrm{Te}$ atoms. The data from the whole isochronal annealing series are given in table II. A slightly different annealing temperature seems to be characteristic for lines $A 1$ and A4, as compared to lines A3 and A5, however, finer temperature steps are needed to prove this in detail.

Low-dose $\left(\approx 10^{12}\right.$ atoms $\left./ \mathrm{cm}^{2}\right)$, room-temperature implantations of ${ }^{119 \mathrm{~m}} \mathrm{Te}$ in silicon single crystals with different oxygen concentrations have been performed. The results are summarized in table III. As the intensity of lines A1, A4, and A5 is relatively low in all implantations, the data are not conclusive as to their dependence on the oxygen content of the host crystal. Because of the low and approximately constant intensity of these lines, they can be neglected in the further analysis of the spectra. The dependence of the intensity of lines $\mathrm{A} 2$ and $\mathrm{A} 3$ on the oxygen content of the host crystal is quite distinct. The intensity of a line $I_{\mathrm{A}}$ is proportional to the population of the site belonging to this line, $p_{\mathrm{A}}$, and to the Debye-Waller factor $f_{\mathrm{A}}$; $I_{\mathrm{A}} \propto p_{\mathrm{A}} f_{\mathrm{A}}$. Therefore, from different experimental intensities of the two lines in two experiments, the ratio of the $f$ factors for the two sites $\mathrm{A} 2$ and $\mathrm{A} 3$ can be estimated if a $1: 1$ relation for the population of sites is assumed (i. e., no other lines are populated, $p_{\mathrm{A} 2}+p_{\mathrm{A} 3}=1$ ). This condition was approximately fulfilled for the implantations in crystals having low and high oxygen contents. From these spectra (labelled by index numbers 1 and 2, respectively), the ratio of the $f$ factors is given by

$$
f_{\mathrm{A} 3} / f_{\mathrm{A} 2}=\left(I_{\mathrm{A} 3}^{1}-I_{\mathrm{A} 3}^{2}\right) /\left(I_{\mathrm{A} 2}^{2}-I_{\mathrm{A} 2}^{1}\right)=0.73(23) \text {. }
$$

This ratio has been adopted in the calculation of the population of sites $\mathrm{A} 2$ and $\mathrm{A} 3$ in table III. The $f$ factor for $\mathrm{Sn}$ on substitutional sites has been measured to be $f_{\mathrm{A} 2}=0.28$ (3) [5] yielding $f_{\mathrm{A} 3}=0.20(7)$.

4. Discussion. - From the implantations of ${ }^{119 \mathrm{~m}} \mathrm{Sn},{ }^{119} \mathrm{Sb}$, and ${ }^{119 \mathrm{~m}} \mathrm{Te}$ in silicon, it can be concluded that the implantation behaviour of Te is different from that of $\mathrm{Sn}$ and $\mathrm{Sb}$. Although $\mathrm{Sb}$ has not been implanted at room temperature and although the relatively poor statistical accuracy of these data does not, for example, exclude an intensity of about ten percent of line $\mathrm{A} 3$, the implantation behaviour of $\mathrm{Sb}$

TABLE II

\begin{tabular}{|c|c|c|c|c|c|}
\hline${ }^{\circ} \mathrm{C}$ & $I_{\mathrm{A} 1}$ & $I_{\mathrm{A} 2}$ & $I_{\mathrm{A} 3}$ & $I_{\mathrm{A} 4}$ & $I_{\mathrm{A} 5}$ \\
\hline- & - & - & - & - & - \\
\hline - & $0.05(2)$ & $0.52(5)$ & $0.34(6)$ & $0.06(2)$ & $0.05(2)$ \\
\hline 200 & $0.05(2)$ & $0.57(5)$ & $0.44(6)$ & $0.05(2)$ & $0.05(2)$ \\
\hline 300 & $0.02(2)$ & $0.65(5)$ & $0.41(6)$ & $0.05(2)$ & $0.06(2)$ \\
\hline 350 & 0.0 & $0.60(5)$ & $0.45(6)$ & $0.05(2)$ & $0.04(2)$ \\
\hline 400 & 0.0 & $0.54(5)$ & $0.47(6)$ & $0.04(2)$ & $0.05(2)$ \\
\hline 500 & 0.0 & $0.84(4)$ & $0.39(6)$ & $0.02(1)$ & $0.05(2)$ \\
\hline 600 & 0.0 & $1.84(4)$ & $0.19(5)$ & 0.0 & $0.01(1)$ \\
\hline 700 & $0.05(2)$ & $1.60(4)$ & $0.29(5)$ & 0.0 & $0.02(1)$ \\
\hline $700\left(^{1}\right)$ & $0.08(3)$ & $0.83(5)$ & $0.53(6)$ & $0.03(1)$ & $0.06(2)$ \\
\hline
\end{tabular}

(1) Measurement performed $\gtrsim 200 \mathrm{~h}$ after annealing, all other spectra measured within $12 \mathrm{~h}$ after annealing; annealing time $20 \mathrm{~min}$.

\section{TABLE III}

Results from room temperature implantations in silicon crystals with different oxygen concentrations

\begin{tabular}{lcccccccc}
\multicolumn{1}{c}{$\begin{array}{c}\text { Oxygen } \\
\text { conc. } \\
\text { atoms } / \mathrm{cm}^{3}\end{array}$} & $I_{\mathrm{A} 1}$ & $\mathrm{I}_{\mathrm{A} 2}$ & $I_{\mathrm{A} 3}$ & $I_{\mathrm{A} 4}$ & $I_{\mathrm{A} 5}$ & $P_{\mathrm{A} 2}$ & $P_{\mathrm{A} 3}$ \\
\multicolumn{1}{c}{ Host crystal } & - & - & - & - & - & - & - & - \\
Vacuum float zone & $\lesssim 10^{15}$ & $0.02(1)$ & $0.58(5)$ & $0.53(4)$ & $0.05(2)$ & $0.02(1)$ & $0.44(4)$ & $0.56(4)$ \\
float zone & $\approx 10^{16}$ & $0.03(3)$ & $0.60(6)$ & $0.37(6)$ & $0.10(4)$ & $0.03(2)$ & $0.54(6)$ & $0.46(6)$ \\
crucible grown & $\approx 10^{18}$ & $0.03(3)$ & $1.05(6)$ & $0.12(4)$ & $0.03(3)$ & $0.03(2)$ & $0.83(5)$ & $0.17(5)$
\end{tabular}


seems to be very similar to that of Sn [3]. The difference between $\mathrm{Sn}$ and Te implants cannot be due to the difference in implantation dose because similar spectra have been observed for both implanted impurities at several other implantation doses and temperatures [3]. Also, the expected distributions and densities of defects produced in the slowing-down process of the heavy ions are the same for all three implants. Therefore, the dissimilarity must be due to different interactions of Te with its surroundings compared to the interactions of $\mathrm{Sn}$ and $\mathrm{Sb}$ with their surroundings. Because of the high defect density in the damage cascades, it is likely that interactions with defects and especially the agglomeration of defects at impurity atoms will be important. The explanation of the lines observed in the Mössbauer spectra of ${ }^{119 \mathrm{~m}} \mathrm{Te}$ in silicon on the basis of different undisturbed regular lattice locations seems to be excluded in view of the systematics of the isomer shifts found for several Mössbauer isotopes in group-IV elements with diamond structure. For implantations of $\mathrm{Te}[1,3], \mathrm{Fe}[8,9]$ and $\mathrm{Co}[10,11]$, two (groups of) lines have been separated and attributed to nearly substitutional and interstitial sites with possibly disturbed surroundings, respectively. According to this rough division, lines $\mathrm{A} 1, \mathrm{~A} 2$, and $\mathrm{A} 3$ should originate from approximately substitutional $\mathrm{Te}$ and A4 and A5 from interstitial Te. As A2 is known to represent the unperturbed substitutional site, this implies that A1 and A3 indicate disturbances of this site. These disturbances are likely to be due to interactions of the Te impurities with defects. This interpretation is supported by the annealing data. The annealing of the defect structures occurs in a temperature range which is typical of the dissociation of defect clusters [12]. However, only defect structures containing $\mathrm{Sb}$ anneal out below $700^{\circ} \mathrm{C}$ while the same structures containing $\mathrm{Te}$ are hardly influenced (with a possible exception of line A4). Similarly, no drastic changes in the Mössbauer spectra of ${ }^{129 \mathrm{~m}} \mathrm{Te}$ upon annealing at 750 and $850^{\circ} \mathrm{C}$ were observed by Hafemeister and de Waard [1, 2]. Hence it follows that relatively stable defect structures are formed by implanted Te. After the radioactive decay of Te, when the $\mathrm{Te}$ atoms have changed to $\mathrm{Sb}$, these structures are less stable. This can be explained by the difference in electronic structure between $\mathrm{Te}$ and $\mathrm{Sb}$. This difference probably also is the reason for their different implantation behaviour. The stability of these defect structures supports the assumption that they are agglomerates with several associated defects rather than simple defect structures of the impurity-vacancy or impurity-interstitial type.
Similar arguments hold for the annealing of lines A4 and A5 if these are interpreted as agglomerates containing interstitial $\mathrm{Te}$. On the other hand, these lines (or fractions of them) might also be due to $\mathrm{Te}$ atoms in regular interstitial sites. In this case, annealing might occur by means of (migrating) vacancies released from the dissociation of defect clusters. This assumption, however, seems less probable because no simple interstitial sites have been found to be populated by $\mathrm{Te}$ atoms from channeling experiments [2,3]. Also, vacancies are released and are mobile at much lower temperatures.

From the implantations of $\mathrm{Te}$ in silicon crystals with different oxygen contents, some indications as to the nature of the defect agglomerates of line $\mathrm{A} 3 \mathrm{can}$ be gained. Oxygen is known to form complicated defect structures with vacancies $[12,13]$. As both $\mathrm{Te}$ and $\mathrm{O}$ are group-VI elements, similar properties might be anticipated for $\mathrm{Te}$. In view of this, line $\mathrm{A} 3$ might tentatively be assigned to a Te-vacancy agglomerate. The decrease of the intensity of line $\mathrm{A} 3$ with increasing oxygen content of the samples can then be explained to be due to the competition of $\mathrm{Te}$ and $\mathrm{O}$ in trapping vacancies. The higher reactivity of oxygen leads to a decrease of defects containing Te. As the dependence of the population of site A3 on the oxygen content is not linear, complicated indirect processes may have to be assumed to account for the observed dependence.

The estimated Debye-Waller factor for the A3 line, which at least is no larger than that for a substitutional site, is in accordance with the above considerations. For a substitutional impurity in silicon, the influence of an adjacent vacancy can roughly be considered as the loss of one of the four hybridized bonds to the nearest neighbours. This loss in bonding can be expected to result in a lowering of the $f$-factor. Also, there will be a tendency of the unshared electrons to go into orbitals which are more stable than $p$ orbitals. Thus an increased electron density at the nucleus will result from a broken bond, in accordance with the experimental findings for the isomer shift of line A3.

It is interesting to compare the results from the annealing of a room-temperature Te-implanted sample to those from implantations at 400 and $450^{\circ} \mathrm{C}$ [3]. In the analysis of the spectra in ref. [3], assuming two lines, it was noted that the linewidth of the substitutional line was about $20 \%$ larger than for similar $\mathrm{Sn}$ implantations. A reanalysis of these spectra with five lines showed that this is due to a small intensity of line A3.

This work has been supported by the Danish State Research Foundation.

\section{References}

[1] Hafemeister, D. W. and DE WAARd, H., Phys. Rev. B 7 (1973) 3014.

[2] Hafemeister, D. W. and DE WAARd, H., Mössbauer Effect
Method., (eds. Gruvermann, I. J., and Seidel, C. W.) 8 (1973) 151.

[3] Weyer, G., Deutch, B. I., Nylandsted Larsen, A., 
Andersen, J. U. and Nielsen, H. L., $J$. Physique Colloq. 35 (1974) C 6-297.

[4] Weyer, G., Deutch, B. I., Nylandsted Larsen, A. and Nxelsen, H. L., Proc. Int. Meet. on Hyperfine Interactions, Leuven 1975, to be published in $H_{y p}$. Int.

[5] Weyer, G., Nylandsted Larsen, A., Deutch, B. I., ANDERSEN, J. U. and ANTONCIK, E., Hyp. Int. 1 (1975) 93.

[6] ANTONCik, E., Hyp. Int. 1 (1976) 329.

[7] WeYer, G., Mössb. Eff. Meth., (eds. Gruvermann, I. J. and Seidel, C. W.) 10 (1976) to be published.

[8] Latshaw, G. L., Sprouse, G. D., Russel, P. B., Kal- vius, G. M. and Hanna, S. S., Bull. Am. Phys. Soc. 13 (1968) 1949.

[9] Latshaw, G. L., Ph. D. Thesis, Stanford University 1971. [10] Weyer, G., Deutch, B. I., Nylandsted Larsen, A. and Holck, O., Proc. Int. Conf. on Mössbauer Spectroscopy, Cracow 1975, (eds. Hrynkiewicz, A. Z. and SAWICKI, J. A.) p. 213, 1975.

[11] Weyer, G., Grebe, G., Kettschau, A., Deutch, B. I., Nylandsted Larsen, A. and Holck, O., $J$. Physique Colloq. 37 (1967) C6-893.

[12] MAYer, J. W., ERIKSSON, L. and DAvies. J. A., Ion Implantation in Semiconductors (Acad. Press, New York) 1970 , p. 200.

[13] BRower, K. L., Rad. Eff. 8 (1971) 213. 